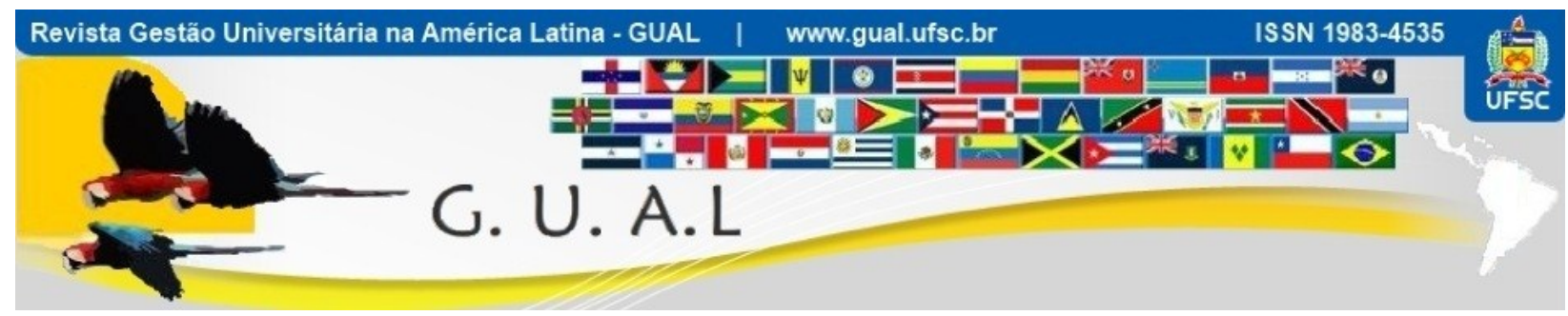

DOI: http://dx.doi.org/10.5007/1983-4535.2012v5n4p209

\title{
PLANEJAMENTO ORÇAMENTÁRIO: AS PRÁTICAS DA UNIVERSIDADE FEDERAL DE LAVRAS
}

\section{BUDGET PLANNING: MANAGEMENT PRACTICES AT FEDERAL UNIVERSITY OF LAVRAS}

\author{
Patrícia Maria Silva, Especialista \\ Universidade Federal de Lavras - UFLA \\ patricia@reitoria.ufla.br \\ Walter Weider de Carvalho, Especialista \\ Universidade Federal de Lavras - UFLA \\ walterwider@hotmail.com \\ Fauze Alvarenga Carvalho, Graduado \\ Universidade Federal de Lavras - UFLA \\ fauze@proplag.ufla.br \\ Renata Pedretti Morais Furtado, Mestre \\ Universidade Federal de Lavras - UFLA \\ renata@dae.ufla.br
}

Recebido em 16/novembro/2012

Aprovado em 07/dezembro/2012

Sistema de Avaliação: Double Blind Review

Esta obra está sob uma Licença Creative Commons Atribuição-Uso. 


\title{
RESUMO
}

O presente artigo traz uma abordagem sobre o planejamento orçamentário praticado na Universidade Federal de Lavras - UFLA. O planejamento é uma ferramenta de auxílio na gestão das instituições que devem possuir uma consciência de se planejar o presente e uma visão de futuro. As decisões e ações futuras, em qualquer tipo de atividade econômica ou de interesse público, devem ser planejadas. O planejamento das instituições públicas brasileiras tem por base o Plano Plurianual do Governo que deve ser executado para atingir o cumprimento das metas estabelecidas pelo governo federal. A UFLA tem seu orçamento baseado no modelo de alocação de recursos orçamentários definido pela Secretaria de Educação Superior (SESu) do MEC, em parceria com a ANDIFES. Na busca pela gestão eficiente dos recursos públicos, pelo aprimoramento da gestão por meio de práticas gerenciais e para maximizar o uso desses recursos, uma parcela do recurso da UFLA é gerida de forma descentralizada, por meio do que se convencionou a chamar "Matriz de Descentralização de Recursos da UFLA" (Matriz-UFLA). A partir da implementação da Matriz-UFLA, houve um avanço na gestão, especificamente na maneira de se planejar e controlar o gasto da OCC Outros Custeio e Capital. Foi possível alocar recursos de maneira equitativa, reconhecendo a competência de cada departamento e evitando a luta por uma "fatia justa" de recursos.

Palavras-chave: Planejamento. Orçamento público. Gestão de recursos públicos.

\begin{abstract}
The present paper presents an approach about the budget planning carried out at Federal University of Lavras (UFLA), in the state of Minas Gerais, Brazil. Having a plan is a helpful tool of institutions management, which must possess a planning vision both about the present and the future. Decision making and future actions in any kind of economic activity or public interest, must be planned. The brazilian public institutions planning depends on the Government long-term planning which must be executed to meet the gools set by the Federal Government. This University, UFLA, has its budget based on the allocation model of budget resources led by Department of Higher Education (SESu) of MEC (Education an Culture Minister) together with National Association of Directors of Federal Institutions of Higher Education (ANDIFES). In searching an efficient management of the public resources, through improving the management using management activities, and to rise the use of those resources, a part of UFLA resource is applied in a decentralized way, which is called "Matrix of decentralization of UFLA resources" (Matrix-UFLA). From the setting of UFLA Matrix, was a management advance, mainly in the way of planning and expenses control of the Occothers cost and capital. It was possible allocate resources in a balanced way, recognizind confrontation for a "fair slice" of resources.
\end{abstract}

Keywords: Planning. Budget public. Public resources management. 


\section{INTRODUÇÃO}

A atividade de planejar faz parte de nosso cotidiano, seja no âmbito pessoal, nas relações sociais, em nosso ambiente profissional ou em relação com os governos e a Administração Pública.

Ao conceituar planejamento, Oliveira (1999), o define como um processo que, considerando a área de atuação, os elementos, o tempo, as unidades organizacionais e suas características, se desenvolve para o alcance de uma situação desejada de modo mais eficiente, eficaz e efetivo, com a melhor concentração de esforços e recursos.

Ainda segundo o autor, a atividade de planejar é complexa em decorrência de sua própria natureza, a de um processo contínuo de pensamento sobre o futuro desejado, e delineamento dos meios efetivos de torná-lo realidade justifica que ele anteceda à decisão e à ação.

As organizações devem possuir, além da consciência de se planejar o presente, uma visão de futuro que almeje para si mesma, uma compreensão de seu papel no mundo, grandes diretrizes e objetivos, e saber desdobrar as metas globais no longo prazo.

No processo de construção do planejamento, princípios teóricos, procedimentos metodológicos e técnicas de grupo são aplicados em organizações que possuem um objetivo e que perseguem a mudança futura. O planejamento não trata apenas das decisões sobre o futuro, mas questiona qual é o futuro das decisões que as organizações tomam.

Segundo Barbosa e Brondani (2005), a "ferramenta" que auxilia a alta administração permitindo nortear ações gerenciais da organização, dentro de um plano previamente determinado de metas a alcançar, e estratégias, diminuindo com isso, a possibilidade de tomada de decisões equivocadas, num mercado extremamente competitivo, é o planejamento estratégico.

As decisões e ações futuras, em qualquer tipo de atividade econômica ou de interesse público, devem ser planejadas. Nos órgãos e entidades estatais, constitui-se como instrumento primordial do planejamento governamental o plano plurianual (PPA). Trata-se de uma inovação da Carta de 1988, que estabelece, de forma regionalizada, as diretrizes, objetivos e as metas da administração pública federal para as despesas de capital, ou investimentos públicos, e para as despesas de duração continuada de dois ou mais exercícios financeiros.

A partir da Constituição Federal de 1988 foi estabelecido o atual sistema de planejamento e orçamento, em que o planejamento plurianual das políticas públicas se articula 
com a execução dos orçamentos anuais e com os instrumentos de controle fiscal. A Constituição trata de planejamento e orçamento de uma forma absolutamente integrada, estabelecendo, em seu art. 165 o PPA, as diretrizes orçamentárias e os orçamentos anuais.

O orçamento público no Brasil, onde estão dispostos as receitas e os gastos administrados pelo Estado, adquiriu importância a partir da Lei $\mathrm{n}^{\circ} 4.320$ de 17 de março de 1964, que estabeleceu as normas gerais de Direito Financeiro para elaboração e controle dos orçamentos e balanços dos entes políticos federados.

Segundo Oliveira (2009) o orçamento evoluiu de uma mera peça de escrituração contábil para um importante instrumento de política econômica, transformando-se, também, em elemento indispensável para o processo de planejamento. Neste processo evolutivo, ainda se constitui um marco, a incorporação da dimensão do planejamento ao orçamento público como um de seus elementos constitutivos. Assim, passou-se a evidenciar não apenas os insumos e os produtos resultantes das despesas orçamentárias, mas também os objetivos dos gastos públicos.

Outro importante instrumento, jurídico, complementar à Constituição foi a Emenda Constitucional $\mathrm{n}^{\circ} 19$, de 4 de junho de 1998, que contribuiu para a implementação de reformas gerenciais no nível federal, e que ficou conhecida como "Emenda da Reforma Administrativa". Esta, contemplou, em especial, a dimensão institucional-administrativa e que deu início a implementação do modelo gerencial no Brasil e da gestão por resultados.

O que de mais representativo houve na evolução do orçamento foram as condições atuais de elaboração e execução do orçamento em função dos avanços dos instrumentos presentes no ordenamento jurídico.

Assim, procura-se nesse artigo descrever e analisar as práticas desenvolvidas pela Universidade Federal Lavras (UFLA) para a gestão de seu orçamento. Para isso organizou-se esse artigo em cinco partes, além desta introdução.

\section{PLANEJAMENTO NO SETOR PÚBLICO}

Segundo Abell (1999), muitas empresas criam sistemas de planejamento sem fazer diferenciação entre o presente e o futuro. Adotam abordagens ineficazes que funcionam como "abrigos de transição" entre presente e futuro, e deixam de atender as necessidades de excelência de curto prazo e às de mudança de longo prazo. O planejamento para o presente necessita de uma estratégia própria e o planejamento para o futuro é feita com base numa visão do futuro, articulando uma estratégia para alcançar as grandes diretrizes e objetivos. 
Como em qualquer instituição, nos órgãos e entidades estatais, o processo de planejamento deve ocorrer de forma semelhante. Embora se deva respeitar certas peculiaridades próprias do setor público, o planejamento no âmbito governamental tratará dos mesmos aspectos que todo plano deve ter: objetivos e metas, meios de realização e meios de avaliação e controle.

Nesse sentido, o planejamento orçamentário, se apresenta como componente de extrema relevância no processo de definição da situação futura a ser realizada e no estabelecimento das formas como esta situação será atingida, constituindo-se parte da essência do planejamento. Com o planejamento orçamentário, é possível verificar a disposição dos recursos para a execução dos trabalhos.

Assim, a realidade do planejamento orçamentário na administração pública brasileira, segundo Pares e Valle (2006), é a de planejamento flexível e intensivo em gestão. O plano é executado por meio dos orçamentos, que por força da integração são transformados em peças estratégicas para as mudanças propostas pelo governo.

Ainda segundo Pares e Valle (2006):

O planejamento estratégico e de longo prazo e a programação orçamentária articulados ao PPA são abordagens necessárias e efetivas ao planejamento, desde que esses horizontes estejam combinados com base em uma carteira de projetos estruturantes. Com essa associação o orçamento adquire caráter estratégico, uma vez que alicerçado em horizontes de planejamento compatíveis com a natureza plurianual das mudanças, com prazo de maturação dos projetos e, particularmente, com a necessidade de gerenciar o risco de incertezas crescentes. (PARES E VALLE, 2006 p.246.).

Embora o PPA seja o plano de maior projeção no processo orçamentário, há ainda outros planos de estatura constitucional, tais como o Plano Nacional de Reforma Agrária (art. 188), Plano Nacional de Cultura (art. 215, $\S 3^{\circ}$ ) e o Plano Nacional de Educação (art. 214).

Estabelecidos no PPA, os programas de governo destinados a atender à sociedade, são dotados de metas a serem alcançadas pelos órgãos públicos, de tal forma que, tomados em conjunto, possam levar a resultados que viabilizem o alcance dos objetivos governamentais mais amplos. Assim atuam as universidades públicas brasileiras, executando seu orçamento para atingir o cumprimento das metas estabelecidas pelo governo federal.

\subsection{ORÇAMENTO PÚBLICO BRASILEIRO}

No âmbito das finanças públicas a evolução e o desenvolvimento da técnica orçamentária são recentes, datando dos dias de atividade do Conselho Federal do Serviço 
Público Civil, criado pela Lei $n^{\circ}$ 284, de 28 de outubro de 1936 e extinto pelo Decreto-lei n579, de 30 de julho de 1938, que organizou o Departamento Administrativo do Serviço Público - DASP, na gestão de Getúlio Vargas, que governou sob um regime político centralizado e autoritário, denominado Estado Novo, com a finalidade de dar o aparato burocrático racionalizador para a administração pública. Uma tentativa de modernizar a burocracia.

Com o DASP buscou-se aprofundar a reforma administrativa destinada a organizar e racionalizar o serviço público no Brasil. As principais funções do DASP, segundo Menon (2010) eram voltadas para: o estudo de todos os setores do governo para uma melhor distribuição do orçamento; organizar a proposta orçamentária anual; fiscalizar a execução orçamentária; selecionar candidatos aos cargos públicos federais; promover a readaptação e aperfeiçoamento dos funcionários; fixar padrões de materiais para uso no serviço público; auxiliar o Presidente da República no exame de projetos de lei; inspecionar os serviços públicos; apresentar anualmente ao Presidente relatório dos trabalhos realizados.

a) Já a Lei $\mathrm{n}^{\mathrm{o}}$ 4.320/64 desempenhou o relevante papel de alçar a concepção moderna dos orçamentos ao plano normativo nacional. Embora ainda não tivesse esquematizado uma lógica de orçamento-programa, a lei impulsionou os primeiros passos em direção a este instrumento, ao tratar explicitamente da programação da despesa e de resultados esperados. O Decreto-Lei n 200 de 25 de fevereiro de 1967, foi mais enfático ao fazer referência expressa ao orçamentoprograma, promovendo a integração planejamento-orçamento por meio dos seguintes instrumentos básicos explicitados em seu art. $7^{\circ}$ : Plano geral de governo;

b) Programas gerais, setoriais e regionais, de duração plurianual;

c) Orçamento-programa anual;

d) Programação financeira de desembolso.

Até então não existia um método inspirado nos modernos princípios de administração, nem linhas de qualquer sistema racionalmente estruturado e organicamente atuante para alocação de recursos. Com a Constituição Federal de 1988, o sistema orçamentário federal passou a ser regulado por três leis:

- Lei do Plano Plurianual (PPA): aprovado por lei quadrienal, sujeita a prazos e ritos diferenciados de tramitação. Tem vigência do segundo ano de um mandato presidencial até o final do primeiro ano do mandato seguinte.

- Lei de Diretrizes Orçamentárias (LDO): de iniciativa exclusiva do chefe do Poder Executivo (no âmbito federal, o Presidente da República, por meio da Secretaria 
de Orçamento Federal). O projeto é então encaminhado ao Congresso Nacional até o dia 15 de abril de cada ano, para aprovação.

- Lei Orçamentária Anual (LOA): o projeto é encaminhado até quatro meses antes do encerramento do exercício financeiro e devolvido para sanção até o encerramento da sessão legislativa.

A formulação da proposta do PPA, segundo Sanches (2006), compreende as seguintes etapas: diagnóstico da realidade presente; o delineamento de cenário futuro desejado; articulação de estratégias para sua realização e das respectivas políticas de apoio; definição de prioridades; formulação de programas de intervenção sobre a realidade (com vistas a atingir os objetivos estabelecidos segundo a ordem de prioridade fixada e dentro dos recursos disponíveis); e o acompanhamento da execução e avaliação dos resultados.

Oliveira (2009), ao tratar do PPA, afirma que o mesmo procurou sanar um dos problemas limitadores do orçamento como instrumento de planejamento, que anteriormente consistia no estabelecimento de meras dotações financeiras, excluindo a definição de metas físicas. Ainda sendo permitido ao PPA sua retificação por lei, durante sua vigência, flexibilizando, portanto, a possibilidade de revisão de seus objetivos e metas.

A fusão, no Brasil, de duas fortes tradições, a de planejamento normativo e a do orçamento-programa, previsto na Lei $\mathrm{n}^{\circ} 4.320 / 64$, segundo Pares e Valle (2006), torna o modelo brasileiro singular se comparado a outras experiências de orçamentos plurianuais, vigentes em muitos países desenvolvidos.

\subsubsection{O orçamento e as universidades federais}

O Plano Nacional de Educação (PNE), em síntese, tem como objetivos a elevação global do nível de escolaridade da população; a melhoria da qualidade do ensino em todos os níveis; a redução das desigualdades sociais e regionais no tocante ao acesso e à permanência, com sucesso, na educação pública e; democratização da gestão do ensino público, nos estabelecimentos oficiais, obedecendo aos princípios da participação dos profissionais da educação na elaboração do projeto pedagógico da escola e a participação das comunidades escolar e local em conselhos escolares ou equivalentes.

Segundo Reis (2011), as universidades federais, para atender às metas do PNE, são levadas a estabelecer políticas acadêmicas para: minorar a evasão escolar, incentivar a criação de cursos noturnos, contribuir para a expansão do sistema federal de ensino superior, pois 
estes serão motivos de avaliação de uma política pública de cujo desempenho também dependerá a alocação de recursos orçamentários.

Em relação aos recursos públicos, no ano de 1991, o Ministério da Educação (MEC) e a Associação Nacional de Dirigentes das Instituições Federais de Ensino Superior (ANDIFES) iniciaram as discussões para a elaboração de uma metodologia para a alocação de recursos orçamentários entre as Instituições Federais de Ensino Superior (IFES) baseada em fórmulas, e dessa forma, garantir a estabilidade dos financiamentos das universidades, assegurar o equilíbrio da alocação orçamentária entre as universidades e efetuar a distribuição de recursos a partir de critérios previamente definidos e divulgados.

Os recursos orçamentários necessários para a manutenção das atividades de ensino nas universidades federais são denominados Outros Custeios e Capital (OCC), que correspondem ao orçamento total da instituição subtraído o recurso para pagamento de pessoal. Esses recursos são repassados com base numa matriz matemática, baseada produtividade acadêmica da universidade.

As discussões, entre MEC e ANDIFES, evoluíram até o modelo adotado atualmente para distribuição de recursos orçamentários de OCC entre as IFES. Modelo esse que é composto por orçamento básico e orçamento de investimento.

O orçamento básico, segundo Reis (2011) é constituído de duas parcelas, a primeira, denominada parcela de manutenção, utiliza um modelo sem partição, considerando a Unidade Básica de Custeio (UBC) multiplicada pelo número de alunos equivalentes ${ }^{1}$ de cada IFES, o que corresponde a $80 \%$ do valor total do orçamento de manutenção. A segunda parcela, denominada Parcela de Qualidade e Produtividade (IQP), utiliza o modelo de partição, considerando indicadores, como o próprio nome sugere, o modelo contempla aspectos qualitativos, mantendo, portanto, um componente que estimula a competição (BRASIL, 2006). Sobre o valor restante do orçamento de manutenção, 20\%, incide o IQP, num sistema de partição pela competitividade.

O orçamento de investimento é constituído, segundo Reis (2011), da Parcela de Equalização e da Parcela de Políticas Públicas e Expansão do Sistema Federal de Ensino Superior, tendo como objetivos a conservação da estrutura física e patrimonial das IFES e o incentivo ao crescimento quantitativo e qualitativo do Sistema Federal de Ensino Superior.

${ }^{1} \mathrm{O}$ aluno equivalente é o principal indicador utilizado para fins de análise dos custos de manutenção das IFES e integra quatro indicadores parciais referentes às atividades educacionais: graduação; mestrado e doutorado stricto sensu; residência médica. 
A partir da definição do modelo de alocação de recursos orçamentários, a Secretaria de Educação Superior do Ministério da Educação (SESu) adota uma matriz de alocação de recursos orçamentários para descentralização de recursos das despesas de custeio e investimentos das IFES.

\section{O ORÇAMENTO DA UFLA E SEU PLANEJAMENTO}

A UFLA, autarquia de regime especial, pessoa jurídica de direito público, regida pela legislação federal vigente, por seu estatuto, pelo regimento geral e pelas resoluções e normas emanadas dos conselhos Universitário e de Ensino, Pesquisa e Extensão tem seu orçamento baseado no modelo de alocação de recursos orçamentários definido pela Secretaria de Educação Superior (SESu) do MEC, em parceria com a ANDIFES.

$\mathrm{Na}$ Constituição Federal em vigor, a autonomia da gestão financeira das universidades federais, está consagrada de forma clara e objetiva, em seu artigo 207, que diz "in verbis":

As universidades gozam de autonomia didático-científica, administrativa e de gestão financeira e patrimonial, e obedecerão ao princípio de indissociabilidade entre ensino, pesquisa e extensão (BRASIL. 2006, p. 138).

A dimensão da autonomia financeira e patrimonial proporciona às universidades a gerência dos recursos alocados à sua disposição, compreendendo a tarefa de elaboração de seus planejamentos, execução e reestruturação de seu orçamento. No entendimento da Consultoria Geral da República (apud SAMPAIO, 1998, p.57):

A autonomia financeira, de caráter instrumental, outorga à universidade o direito de gerir e aplicar seus próprios bens e recursos, em função de objetivos didáticos, científicos e culturais já programados.

Segundo Ghelman e Costa (2006) para as organizações públicas, a perspectiva financeira não é o objetivo final, mas sim, um meio para obtenção de recursos necessários ao cumprimento de sua função social. A boa execução orçamentária e a ampliação da captação de recursos financeiros são fatores essenciais para tornar uma instituição pública mais sólida e apta a cumprir sua missão. Por isso, no setor público a perspectiva financeira, ao invés de estar focada no lucro, está orientada para a execução do orçamento. 


\subsection{A GESTÃO DOS RECURSOS NA UFLA}

Até o ano de 2008, a distribuição dos recursos públicos internos à UFLA não contemplava métodos que valorizassem o mérito, a eficiência ou mesmo a real necessidade do recurso nos diversos departamentos que a compõe. A gestão dos recursos permanecia centralizada nas mãos do ordenador de despesas, que possui o poder de definir os critérios de distribuição. Critérios esses que muitas vezes podem privilegiar o bem estar das relações políticas dentro de qualquer organização. O planejamento era executado de forma empírica, não existiam critérios que pudessem quantificar o que cada setor ou departamento necessitava para melhorar a qualidade do ensino, pesquisa e extensão.

Na busca pela gestão eficiente dos recursos públicos, pelo aprimoramento da gestão por meio de práticas gerenciais e para maximizar o uso desses recursos, uma parcela é gerida de forma descentralizada, por meio do que se convencionou a chamar "Matriz de Descentralização de Recursos da UFLA” (Matriz-UFLA).

Com a implantação da Matriz-UFLA, parte da responsabilidade da gestão dos recursos foi transferida aos departamentos didático-científicos com o objetivo de também dinamizar os processos internos com o pressuposto de que os departamentos conhecem a real hierarquia de suas necessidades e poderão gerenciar os recursos contribuindo para o aumento da eficiência do gasto do recurso público.

A essência de todo o processo está em uma dinâmica, em que o início se encontra justamente dentro dos departamentos. Departamentos mais eficientes no ensino propiciarão menores índices de retenção e um maior número de alunos diplomados, melhorando o desempenho da Instituição perante o MEC, refletindo em maiores incrementos financeiros de OCC para a UFLA e por consequência na Matriz-UFLA.

Esse processo representa a estratégia própria da Instituição, delineada para direcionar como ela deve funcionar hoje, dadas suas competências e prioridades, para atingir as metas estabelecidas em seu planejamento para o futuro, fundamentado no plano de expansão da Instituição.

\subsection{FORMULAÇÃO}

Baseando-se na Matriz Orçamentária do Governo Federal, a UFLA implementou, no ano de 2009, sua própria matriz de alocação de recursos orçamentários, custeio e capital.

Com a crescente escassez dos recursos orçamentários destinados às universidades públicas, torna-se cada vez mais evidente a necessidade de 
tornar os instrumentos de controle, como o orçamento anual e sua alocação aos departamentos, mais descentralizados, transparentes, e de coresponsabilização, melhorando a performance das atividades primárias de ensino, pesquisa e extensão.(PIRES, ROSA e SILVA,2010, p.240).

Na Matriz-UFLA, são considerados diversos parâmetros calculados sobre uma base de dados de caráter acadêmico e científico que busca valorizar o desempenho de cada departamento didático-científico, sob a gestão do chefe de departamento e de um administrador. O objetivo da UFLA, com a criação de sua própria matriz, é dar maior autonomia, sustentabilidade financeira e suporte aos cursos de graduação, a exemplo do que contempla a matriz da SESu, elaborada juntamente com ANDIFES.

O modelo da ANDIFES adotado pelo MEC/SESu para as IFES é concebido em função do número de alunos equivalentes das instituições, que é calculado com base na seguinte fórmula:

Fórmula para cursos de graduação consolidados ${ }^{2}$

$$
N f t e_{(G)}=\left\{\left[N_{d i} \times D \times(1+R)\right]+\left[\left(\frac{N_{i}-N_{d i}}{4}\right) \times D\right]\right\} \times B T \times B F S \times P G
$$

Onde,

$\mathrm{Nfte}_{(G)}=$ Número de alunos equivalentes (graduação);

$N_{d i}=$ Número de diplomados;

$D=$ Duração média do curso;

$R=$ Coeficiente de retenção;

$N_{i}=$ Número de ingressantes;

$B T=$ Bônus por turno noturno;

$B F S=$ Bônus por curso fora da sede;

$P G=$ Peso do grupo.

Sendo, D e R informados pelas instituições de ensino e PG é uma subdivisão dos cursos em áreas de custos para tornar possível a diferenciação entre cursos de maiores custos em relação aos demais.

$$
\text { Fórmula para cursos novos }{ }^{3} \text { ou intervalados } 4
$$

$$
\mathrm{Nfte}_{(G)}=N M R \times B T \times B F S \times P G
$$

Onde,

$\mathrm{Nfte}_{(G)}=$ Número de alunos equivalentes (graduação);

$N M R=$ Número de alunos matriculados efetivos no ano de referência do cálculo;

${ }^{2}$ Curso consolidado é aquele que possui pelo menos uma primeira turma formada.

${ }^{3}$ Cursos novos são aqueles que não completaram ainda o tempo de existência suficiente para ter a primeira turma formada

${ }^{4}$ Cursos intervalados são aqueles que por condições específicas de operacionalização, ocorrem interrupções de ingressantes e de diplomados simultaneamente, independente da data de início do curso. 
$B T=$ Bônus por turno noturno;

$B F S=$ Bônus por curso fora da sede;

$P G=$ Peso do grupo.

Fórmula para curso de mestrado Stricto Sensu

$$
\mathrm{Nfte}_{(M)}=N M \times f M D \times P G
$$

Onde,

$\mathrm{Nfte}_{(M)}=$ Número de alunos equivalentes (mestrado);

$N M=$ Número de alunos matriculados efetivos do mestrado;

$f M D=$ Fator de tempo dedicado a cursar disciplinas;

$P G=$ Peso do grupo.

Sendo, $f M D=0,75$

Fórmula para curso de doutorado

$$
\mathrm{Nfte}_{(D)}=N D \times f D D \times P G
$$

Onde,

$\mathrm{Nfte}_{(D)}=$ Número de alunos equivalentes (doutorado);

$N D=$ Número de alunos matriculados efetivos do doutorado;

$f D D=$ Fator de tempo dedicado a cursar disciplinas;

$P G=$ Peso do grupo.

Sendo, $f D D=0,38$

Assim, com os aprimoramentos e adaptações necessárias, a UFLA acrescentou índices que consideram outras atividades, como a extensão da infraestrutura física de cada departamento, a produção científica, e a extensão universitária.

A Matriz-UFLA, Fórmula 5, traz em seu contexto diversos indicadores calculados sobre uma base de dados de caráter acadêmico, científico e de parâmetros que visam valorizar o desempenho de cada departamento.

Fórmula da Matriz-UFLA

$$
M=[(\text { NFTed X 0,7) }+(\text { Prod. X 0,1 })+(\text { Ext. X 0,1 })+(\text { Área X 0,1) }] \text { x }(1+\text { FE })
$$

Onde,

NFTed - Aluno equivalente por departamento

Prod. - Produção científica por departamento

Ext. - Produção extensionista por departamento

Área - Área física por departamento

FE - Fator de eficiência

Os índices que compõem essa Fórmula são: 
NFTed: baseado no Nfte disponibilizado pelo MEC/SESu, porém no âmbito da UFLA, constitui-se na distribuição percentual dos alunos em cada departamento no decorrer de seu curso, de acordo com as disciplinas frequentadas. O NFTed representa $70 \%$ do total da matriz.

Prod: são analisados os artigos publicados em revistas pelos docentes, levando em consideração o fator de impacto da revista; número de livros publicados; capítulos de livros; depósito de patentes; registro de softwares e cultivares; projetos financiados, dados estes obtidos no Currículo Lattes. A pontuação total é dividida pelo número total de docentes pertencentes ao departamento. A Prod. representa $10 \%$ do total da matriz.

Ext: Os dados são fornecidos pela Pró-Reitoria de Extensão e Cultura - PROEC, tendo como base os trabalhos cadastrados na PROEC. Cada item de extensão recebe uma pontuação diferenciada. A pontuação total é dividida pelo número total de docentes pertencentes ao departamento. A Ext. representa $10 \%$ do total da matriz.

Área: Os dados são fornecidos pela Prefeitura Universitária. Em áreas como galpões e casas de vegetação foi aplicado fator de correção de 0,25 . A Área representa $10 \%$ do total da matriz.

FE: determinado como o inverso do índice de retenção média das disciplinas ofertadas pelo departamento.O fator varia de 0 a 1 .

\subsection{IMPLEMENTAÇÃO}

Para implementação do modelo da Matriz-UFLA, os administradores e chefes de departamento contam com apoio de um sistema desenvolvido pela equipe da Diretoria de Gestão de Tecnologia da Informação, por meio do qual a Pró-Reitoria de Planejamento e Gestão (PROPLAG) pode aprovar e acompanhar o plano de aplicação de recursos que é exigido dos departamentos.

No plano de aplicação dos recursos algumas regras as quais dizem respeito à distribuição feita entre rubricas, devem ser seguidas, as quais para o ano de 2012 foram: Rubrica: 33.90.14 - Diárias (Proporção de apropriação: 5\%); Rubrica: 33.90 .30 - Material de Consumo (Proporção de apropriação: Livre); Rubrica: 33.90 .33 - Passagens e Despesas com Locomoção (Proporção de apropriação: 5\%); Rubrica: 33.90 .39 - Despesas compulsórias (Proporção de apropriação: 30\%); Rubrica: 33.90 .39 - Outros Serviços de Terceiros - Pessoa Jurídica (Proporção de apropriação: livre); Rubrica: 44.90 .52 - Equipamentos e Material Permanente (Proporção de apropriação: 30\%).

Alterações são possíveis de serem efetuadas no decorrer do exercício, bastando uma autorização da PROPLAG, que antes analisa a possibilidade de atendimento das mesmas. Sendo possível, a alteração é feita no sistema, que automaticamente disponibiliza para a unidade proponente a opção de alterar o item em seu plano de aplicação. 
A partir da aprovação do plano de aplicação dos recursos, a execução financeira é de responsabilidade de cada departamento. Processo esse que se inicia com o envio dentro dos prazos pré-determinados, do formulário de pedido de compras à Diretoria de Gestão de Materiais (DGM), responsável por todo o processo licitatório para aquisição de materiais e serviços, rubricas 33.90.30, 33.90.39 e 44.90.52. Já para as rubricas 33.90.14 e 33.90.33, é criada pela Diretoria de Contabilidade, Orçamento e Finanças uma Unidade de Gestão no Sistema de Concessão de Diárias e Passagens (SCDP), com o valor aprovado no plano de aplicação de recursos da unidade administrativa. Por último, os valores da rubrica 33.90.39, são descontados pela PROPLAG diretamente no plano de aplicação.

\subsection{AVALIAÇÃO}

Sob o ponto de vista da administração, a partir da implementação da Matriz-UFLA, houve um avanço na gestão, especificamente na maneira de se planejar e controlar o gasto da OCC. Foi possível alocar recursos de maneira equitativa, reconhecendo a competência de cada departamento e evitando a luta por uma "fatia justa" de recursos. Para o ordenador de despesas a aplicação dos recursos com base na Matriz-UFLA permitiu o abandono das práticas clientelistas e adoção de critérios técnicos para melhor aplicação dos escassos recursos públicos.

Sob o ponto de vista dos departamentos, possibilitou aos chefes mais autonomia, já que não se faz necessário "bater à porta" para conseguir recursos necessários à gestão dos departamentos. Abriu-se, também, a possibilidade destes implementarem seu próprio planejamento interno, avaliando suas reais necessidades tanto quanto à quantidade de insumos quanto ao tempo de atendimento de suas demandas e assim assumindo, também, a responsabilidade pelo gasto eficiente dos recursos.

A Matriz-UFLA tem permitido maior transparência, eficiência e objetividade nos critérios internos de distribuição dos recursos recebidos de OCC pela UFLA.

\subsection{O PLANEJAMENTO}

O planejamento da UFLA está em consonância com o PDI - Plano de Desenvolvimento Institucional, nas versões 2005-2010 e 2011-2015, o qual é apresentado no Plano de Ampliação Acadêmica, que tem por objetivo o desenvolvimento das ações no ensino de graduação e pós-graduação, bem como a ampliação do suporte às ações de pesquisa e extensão da UFLA. Este plano estabelece as diretrizes para o incremento de cursos de 
graduação nas modalidades presencial e a distância, por meio das possibilidades viabilizadas com recursos federais, respaldadas nos termos da Lei nº 9394/96 - Lei de Diretrizes e Bases da Educação Nacional e no Plano Nacional de Educação (PNE) para o período de 2011-2020, que apresenta metas para a evolução da educação brasileira nos próximos 10 anos, sempre balizadas pela qualidade como seu eixo norteador.

As diretrizes da UFLA estão centradas na expansão da oferta de vagas na graduação, assegurando uma base real de qualidade, promoção de estudos que apontem alternativas para criação de novos cursos, priorizando cursos com importantes impactos em níveis regional, estadual e nacional e habilitações que envolvam os departamentos e promovam a transdisciplinaridade, bem como criando condições para a implantação de cursos de graduação a distância.

O planejamento da UFLA também está em consonância com o PNE, 2011-2020. Plano no qual a expansão de oferta de matrículas no setor público da educação superior e mais investimentos em ciência e tecnologia são estratégias primordiais para propiciar oportunidades aos jovens e promover a inclusão social, o desenvolvimento nacional e a superação das desigualdades territoriais de forma a favorecer a melhoria de qualidade de vida da população. Deve ser levado em consideração, segundo os elaboradores do Mapa Estratégico da Indústria (2005-2017), que o maior valor agregado da produção hoje provém do conhecimento e que a inovação é uma estratégia-chave para o desenvolvimento econômico e implica em constantes mudanças sendo a educação o elemento essencial para a inclusão social e política, por ser imprescindível ao exercício da cidadania.

De acordo com o PNE, tem-se como meta elevar a taxa bruta de matrícula na educação superior para $50 \%$ e a taxa líquida para $33 \%$ da população de 18 a 24 anos, assegurando a qualidade da oferta. Dentre as estratégias definidas para o cumprimento desta meta, a proposta ora apresentada contempla: o aperfeiçoamento da capacidade instalada da estrutura física e de recursos humanos das instituições públicas de educação superior mediante ações planejadas e coordenadas, de forma a ampliar e interiorizar o acesso à graduação; ampliação da oferta de vagas por meio da expansão e interiorização da rede federal de educação superior, da Rede Federal de Educação Profissional, Científica e Tecnológica e do Sistema Universidade Aberta do Brasil; a oferta de educação superior pública e gratuita prioritariamente para a formação de professores para a educação básica, bem como para atender o déficit de profissionais em áreas específicas; oferta de formação de 
pessoal de nível superior considerando as necessidades do desenvolvimento do país, a inovação tecnológica e a melhoria da qualidade da educação básica.

\subsection{DOS RECURSOS NECESSÁRIOS}

A base para financiar a manutenção das instituições públicas de ensino superior é a matriz orçamentária do governo federal, cujos recursos disponibilizados para a UFLA são insuficientes para viabilizar seu plano de expansão.

Nesse contexto, faz-se necessária a apresentação junto ao Ministério da Educação de planos de trabalho que busquem justificar o investimento na UFLA. E que, assim, por meio destes, possibilitar a complementação dos recursos orçamentários necessários para o cumprimento das metas propostas no planejamento.

Outra estratégia, para conseguir os recursos imprescindíveis para a manutenção da Instituição, é, a cargo da Direção Executiva da UFLA, identificar os elementos que compõem o Índice Geral de Cursos da Instituição (IGC), os quais serão alvo de ações diretas para sua melhoria.

O IGC foi instituído pela Portaria Normativa $\mathrm{n}^{\mathrm{o}} 12$ de 5 de setembro de 2008, emitida pelo MEC. Esse indicador, de acordo com sua Portaria, consolida informações relativas aos cursos superiores constantes dos cadastros, censo e avaliações oficiais disponíveis no Instituto Nacional de Estudos e Pesquisas Anísio Teixeira (INEP) e na Coordenação de Aperfeiçoamento de Pessoal de Nível Superior (CAPES).

De acordo com a Portaria que o instituiu, o IGC irá se utilizar da média ponderada dos Conceitos Preliminares de Cursos (CPC), sendo a ponderação determinada pelo número de matrículas em cada um dos cursos de graduação correspondentes, e da média ponderada das notas dos programas de pós-graduação, obtidas a partir da conversão dos conceitos fixados pela CAPES, sendo a ponderação baseada no número de matrículas em cada um dos cursos ou programas de pós-graduação strictu sensu correspondente. A Portaria evidencia nos dois primeiros parágrafos do Artigo $2^{\circ}$ que a ponderação levará em conta a distribuição dos alunos dasInstituições de Ensino Superior entre os diferentes níveis de ensino (graduação, mestrado e doutorado) e que, nas instituições sem cursos ou programas de pós-graduação avaliados pela CAPES, o IGC será calculado na forma do inciso I.

A partir da análise dos elementos que compõem o IGC, busca-se criar um índice de avaliação da eficiência da alocação de recursos da Matriz-UFLA, visando a aplicação direcionada para as reais necessidades de cada departamento, e com isso melhorar o ensino de 
graduação, que impacta diretamente no Número de Aluno Equivalente (Nfte). O Nfte é o principal indicador utilizado para fins de análise dos custos de manutenção das IFES, nas rubricas referentes ao orçamento de OCC.

Assim, é fundamental que os gestores da UFLA e de outras IFES planejem, conheçam, acompanhem, e se estruturem em favor do melhor desempenho nas variáveis que compõem o IGC, OCC e todos os elementos que possam servir como base para a definição de novas possibilidades de incrementos orçamentários para manutenção de suas atividades.

\section{CONSIDERAÇÕES FINAIS}

Na busca do cumprimento das metas estabelecidas pelo governo federal, no Plano Plurianual e no Plano Nacional de Educação, a UFLA tem suas ações orientadas para dois horizontes temporais. O primeiro, orientado para o futuro, por meio do Plano de Ampliação Acadêmica que necessita de um aporte orçamentário distinto por parte do governo federal para que se realize, o qual demanda da UFLA competência para a elaboração de um plano que de fato justifique sua realização.

O segundo horizonte no qual, internamente, a UFLA desenvolve as ações necessárias, com vistas à melhoria da qualidade do ensino, mais importante, ou talvez, a única ação que garantirá os recursos necessários à sua atual estrutura e àquela desejada no futuro.

As práticas de gestão do orçamento desenvolvidas, hoje, na UFLA, estão focadas em aprimorar suas capacidades gerenciais em favor da incorporação efetiva do modelo descentralizado de orçamento em seus hábitos e rotinas para que se tenha, como resultado final, acréscimos financeiros no orçamento da UFLA.

Seu orçamento é composto de forma mais representativa pela OCC, programas especiais do governo, projetos específicos elaborados pela Direção Executiva da UFLA, e também, pelas rendas próprias da Instituição e emendas parlamentares. Utilizado para a manutenção das atividades da Instituição em todos os seus níveis e, também, para financiar sua expansão. Parte dos recursos são gerenciados de forma descentralizada.

A descentralização dos recursos realizada por meio da Matriz-UFLA, compartilha a responsabilidade com os departamentos didático-científicos, tanto quanto no planejamento, quanto na utilização eficiente dos recursos que compõem o orçamento da UFLA.

Por consequência espera-se a melhoria do ensino de graduação. Com recursos gerenciados pelos próprios departamentos, os quais conhecem a real hierarquia de suas necessidades, estes podem geri-los de forma a contribuir mais efetivamente para a melhoria 
do ensino, impactando na melhoria dos índices de classificação da UFLA, propiciando melhores resultados nas avaliações das diversas variáveis e elementos que compõem os índices que classificam o ensino superior no Brasil.

A melhoria do ensino e dos índices de classificação propiciará, também, aumento nos recursos de OCC em virtude da melhoria de variáveis como o número de alunos ingressantes, concluintes, taxas de retenção e taxas de evasão, entre outros. Tais melhorias resultarão em aumento nos recursos de custeio e capital no orçamento da UFLA.

Portanto, é essencial que as IFES implementem políticas focadas na melhoria do ensino que é a base para a composição e expansão de seu orçamento. Políticas essas, que devem ser norteadas pelos princípios da administração pública gerencial, uma vez que seu foco recai sobre o alcance de resultados e prestação de serviços públicos de qualidade, com eficiência.

\section{REFERÊNCIAS BIBLIOGRÁFICAS}

ABELL, D. Duplo planejamento. Revista HSM Management. 3, n.16, set/out. 1999.

BARBOSA, R. E; BRONDANI, G. Planejamento Estratégico Organizacional. Revista Eletrônica de Contabilidade. Vol. I. n. 2. Dez/2004 - Fev/2005.

BRASIL. Constituição da República Federativa do Brasil: promulgada em 5 de outubro de 1988. 38 ed. atual. São Paulo: Saraiva, 2006.

BRASIL, Decreto-Lei n 200, de 25 de fevereiro de 1967. Dispõe sobre a organização da Administração Federal, estabelece diretrizes para a Reforma Administrativa e dá outras providências. Diário Oficial [da República Federativa do Brasil], Brasília, DF,27fev. 1967.

BRASIL, Emenda Constitucional n 19, de4 de junho de 1998. Modifica o regime e dispõe sobre princípios e normas da Administração Pública, servidores e agentes políticos, controle de despesas e finanças públicas e custeio de atividades a cargo do Distrito Federal, e dá outras providências.Diário Oficial [da República Federativa do Brasil], Brasília, DF, 5jun. 1998.

BRASIL, Lei n 4320, de 17 de março de 1964. Estatui Normas Gerais de Direito Financeiro para elaboração e controle dos orçamentos e balanços da União, dos Estados, dos Municípios e do Distrito Federal.Diário Oficial [da República Federativa do Brasil], Brasília, DF, 17 mar. 1964.

GHELMAN, S; COSTA, S. R. da.Adaptando o BSC para o setor público utilizando os conceitos de efetividade, eficácia e eficiência. XIII SIMPEP - Bauru, SP, Brasil, 6 a 8 de Novembro de 2006.

MENON, G. A tentativa de racionalização do estado brasileiro na era Vargas: uma breve análise sobre o DASP. Rev. FIDES, Natal, v. 1, n. 2, ago./dez. 2010. 
OLIVEIRA, D. P. R. Planejamento estratégico: conceitos, metodologias e práticas. São Paulo: Atlas, 1999.

OLIVEIRA, F. A. Economia e política das finanças públicas no Brasil. São Paulo:Hucitec, 2009.

PARES, A; VALLE, B. A retomada do planejamento governamental no Brasil e seus desafios. In.: GIACOMONI, J; PAGNUSSAT, J. L. (orgs.). Planejamento e orçamento governamental. Brasília: ENAP, p. 229-270, vol. 1, 2006.

REIS, C. Z. T. Estágios da institucionalização do modelo de alocação de recursos orçamentários das universidades federais brasileiras. Viçosa, MG, 2011.

SANCHES, O. M; O ciclo orçamentário: uma reavaliação a luz da Constituição de 1988. In.: GIACOMONI, J; PAGNUSSAT, J. L. (orgs.). Planejamento e orçamento governamental. Brasília: ENAP, p. 187-217, vol. 2, 2006.

SAMPAIO, A. L. B. de. Autonomia universitária na doutrina brasileira. In: .Autonomia universitária: um modelo de interpretação e aplicação do artigo 207 da Constituição Federal. Brasília, DF: Ed. Universidade de Brasília, DF, 1998. cap. 3, p. 88-120. 